\title{
Promoting audit in primary care: roles and relationships of medical audit advisory groups and their managers
}

\author{
Charlotte Humphrey, Diane Berrow
}

\begin{abstract}
Objectives-To investigate perceptions of family health service authorities and medical audit advisory groups of advisory groups' involvement in clinical audit and wider quality issues; communication with the authorities; and manager satisfaction. Design-National postal questionnaire survey in 1994.
\end{abstract}

Setting-All family health services authority districts in England and Wales. Subjects-Chief executives or other responsible authority officers and advisory group chairpersons in each district.

Main measures-Priorities of advisory group and authority for audit; involvement of advisory group in wider quality issues; communication of information to, and contacts with, the authority and its involvement in planning the future work of the advisory group; and authorities' satisfaction.

Results-Both groups' views about audit were similar and broadly consistent with current policy. Advisory group involvement in wider quality issues was extensive, and the majority of both groups thought this appropriate. Much of the information about their activities collected by advisory groups was not passed on to the authority. The most frequent contact between the two groups was the advisory group's annual report, but formal personal contact was the most valued. Most authority respondents thought their views had been recognised in the advisory group's planning of future work; only a small minority were not satisfied with their advisory groups. Dissatisfied respondents received less information from their advisory groups, had less contact with them, and thought they had less input into their plans. There was some evidence that advisory groups in the "dissatisfied districts" were less involved in clinical audit and with their authorities in wider quality issues.

Conclusions-Most advisory groups are developing their activities in clinical audit and have expanded their scope of work. The quality and availability of information about progress with audit is a cause for concern to both groups.

(Quality in Health Care 1995;4:166-173)

Keywords: medical audit advisory group, family health services authorities, primary care audit

Medical audit advisory groups were set up in 1990 to facilitate the development of audit in general practice. At that time the focus was on unidisciplinary medical audit, the choice of audit topics was regarded as a matter for the participating doctors, and health service managers had minimal involvement in the activities of the advisory groups. Since then important changes have occurred in national audit policy, including a shift of emphasis towards multidisciplinary clinical audit, an assumption that audit should be directed, at least partly at local and national health service priorities, and an expectation of increased management participation in defining audit strategy and using its findings (table 1).
Health Policy

Evaluation Unit, University Department of Public Health, Royal Free Hospital School of Medicine, London NW3 2PF

Charlotte Humphrey, lecturer in medical sociology

Diane Berrow, research officer

Correspondence to:

Ms Humphrey

Accepted for publication 7 April 1995
Table 1 Developments in primary care audit policy ${ }^{1-5}$

\begin{tabular}{|c|c|c|}
\hline & Policy document & Key points \\
\hline 1989 & $\begin{array}{l}\text { Working for Patients' } \\
\text { (government white paper) }\end{array}$ & Medical audit introduced as a central feature of NHS policy \\
\hline 1990 & $\begin{array}{l}\text { Medical audit in the family } \\
\text { practitioner services } \\
(\mathrm{HC}(\mathrm{FP})(90) 8)^{2} \text { (health circular) }\end{array}$ & $\begin{array}{l}\text { Each family health services authority to set up a medical audit advisory group to } \\
\text { facilitate the development of audit in general practice. Advisory group members to be } \\
\text { mainly general practitioners, with representation from public health and hospital } \\
\text { medicine. Audit to be professionally led. Advisory group to report regularly to family } \\
\text { health services authority on the general results of the audit programme. No formal } \\
\text { expectation of family health services authority input into advisory group strategy or } \\
\text { membership of the group }\end{array}$ \\
\hline 1993 & $\begin{array}{l}\text { Clinical audit: meeting and } \\
\text { improving standards in health care }{ }^{3} \\
\text { (NHSME discussion document) }\end{array}$ & $\begin{array}{l}\text { Shifted emphasis from uniprofessional medical audit to multiprofessional clinial audit. } \\
\text { Audit to remain professionally led, but the management contribution to audit strategy } \\
\text { to be enhanced }\end{array}$ \\
\hline 1994 & $\begin{array}{l}\text { Clinical audit: } 1994-5 \text { and beyond } \\
\text { EL( } 94) 20^{4} \\
\text { (NHSME executive letter) }\end{array}$ & $\begin{array}{l}\text { Guidance on the practical steps to be taken to support the development of clinical } \\
\text { audit and recommendation of development of an agreed contract between family } \\
\text { health services authority and advisory group }\end{array}$ \\
\hline 1994 & $\begin{array}{l}\text { Letter from NHSME to advisory } \\
\text { groups s }\end{array}$ & $\begin{array}{l}\text { Extended provisions of } 1990 \text { circular regarding arrangements for advisory groups to } 31 \\
\text { March } 1996 \text {. Emphasised need for advisory groups to encourage multidisciplinary, } \\
\text { interpractice, and interface audit between primary and secondary care. Encouraged } \\
\text { advisory groups to develop business plans }\end{array}$ \\
\hline
\end{tabular}


Family health services authorities *

- Responsible for services provided by general practitioners, and National Health Service dentists, pharmacists, and opticians. Receive funds from, and are accountable to, the regional health authority

- 96 family health services authorities existed in England and Wales in 1994

Main functions

- Administer the nationally negotiated contracts of general practitioners and National Health Service dentists, pharmacists, and opticians

- Manage cash limited budgets for general practitioner premises and practice staff

- Manage the general practitioner indicative prescribing scheme

- Maintain lists of patients registered with general practitioners

- Define the primary healthcare needs of the area (in collaboration with the district health authority) and produce plans to meet those needs

- Investigate complaints against family practitioners

*Family health services authorities will merge with district health authorities in April 1996

\section{Medical audit advisory groups}

- Set up in 1990 in every family health services authority district in England and Wales

- Constituencies vary in size from fewer than 20 practices to more than 350 practices

\section{Membership}

- Chaired by a general practitioner and include up to 12 doctors, most of whom are local general practitioners

- Most include representation from hospital medicine and public health. Some include representatives of the wider primary healthcare team and the general public

\section{Responsibilities}

- To institute regular, systematic medical audit in which all practitioners take part

- To establish procedures to ensure confidentiality of audit results for individual patients and doctors

- To establish appropriate mechanisms to ensure that problems disclosed through audit are solved

- To provide a regular report to the family health services authority on the general results of the audit programme

Funding

- Budget allocation from the family health services authority (average allocation in 1992-3 was $£ 71640$ )

\section{Activities}

- Most advisory groups use a combination of approaches to promote audit in their district, including individual practice visits, geographical patch work, topic groups, interpractice audits, districtwide audits, education and training, and practical help

As they have evolved advisory groups have moved beyond their original brief in several ways which reflect these changing expectations. For example, many have extended their membership to include members of the wider primary healthcare team and have developed closer links with their family health services authorities than are formally required. For their part, managers of family health services authorities have shown increasing interest in encouraging advisory groups to take account of their priorities for audit and to cooperate in wider aspects of practice development. ${ }^{6}$ The NHS Executive encouraged advisory groups to shift the emphasis of their work towards multidisciplinary and interface audit work and to agree business plans with their family health services authorities. ${ }^{5}$ Presently, however, all such developments are locally negotiated as no formal changes have been made to the provisions of the original circular regarding the structure, activities, and accountability of advisory groups. ${ }^{2}$

What will happen to advisory groups when the new unitary health authorities come into being in April 1996 and responsibilities for primary and secondary care audit are amalgamated in one organisation is not yet clear, but professional support for audit will probably continue to be required. The recently published report of the primary care working group of the Department of Health's clinical outcomes group proposed that facilitation of clinical audit in primary care should become part of a wider range of support for quality assurance and development available to practices and suggested replacing or restructuring advisory groups to reflect the arrangements required to bring these functions together. ${ }^{7}$ The report argues against central directives on the structure of such support but favours locally developed contractual arrangements which build on the experience already gained. It calls for several models of supporting clinical audit and service development to be explored, with particular regard to their functions, accountability arrangements, and the preferences of local stakeholders. As a starting point the advisory group itself needs to be explored in these terms, so that consideration of alternatives is informed by knowledge of the nature, strengths, and limitations of what presently exists.

The aim of this study was to obtain some systematic information on how advisory groups nationally have responded to the changing needs and demands of the health service environment and how these responses are perceived by the family health services authority managers to whom advisory groups are accountable. Specific objectives were to investigate the perceptions of both groups of the commitment of advisory groups to clinical audit and their involvement with the family health services authorities in wider quality issues; to explore the nature and acceptability of arrangements for informing managers about, and involving them in, the work of their advisory groups; and to consider reasons for variations in manager satisfaction.

\section{Subjects and methods}

We sent postal questionnaires to all family health services authorities and advisory group chairpersons in England and Wales in May 1994. The family health services authority questionnaire was intended for completion by 


\section{Questionnaire content}

Advisory group and family health services authority questionnaires contained five main subsections:

\section{Advisory group strategies for promoting audit}

For each item on a list of different aspects of audit all respondents were asked to state $(a)$ whether or not the advisory group was presently promoting this aspect and $(b)$ whether it should be a priority for the advisory group in the future (irrespective of the answer given to $(a)$ )

2 Wider quality issues

Besides their remit for audit, several other ways advisory groups might work with family health services authorities to improve quality of care have been suggested. For each item on a list of potential areas of help all respondents were asked to state (a) whether or not the advisory group was presently advising or helping the family health services authority in this way and $(b)$ in areas where the advisory group was not presently involved, whether such involvement would be appropriate (advisory group respondents) or valuable (family health services authority respondents)

3 Information about the advisory group's activities

For each of a list of possible types of information advisory group respondents were asked to state $(a)$ whether the advisory group collected this type of information and $(b)$ whether or not it passed it on to the family health services authority. Family health services authority respondents were not asked what types of information they presently received. Instead, for each item in the list they were asked to state whether they did find it valuable (those receiving information) or would find it valuable (those not receiving information)

4 Mechanisms for maintaining contact between advisory group and family health services authority

For each of a list of possible forms of contact all respondents were asked to state $(a)$ whether or not this form of contact applied locally and $(b)$, if it did apply, whether it was valuable

\section{Planning future work of the advisory group}

All respondents were asked whether family health services authority views about what the advisory group should do in future had been sought by the advisory group, whether their views had been taken account of by the advisory group; and, if so, how

For each subsection in both questionnaires an open ended question asked respondents to describe any concerns or reservations.

In addition, subsections 1, 3, 4 and 5 of the family health services authority questionnaire were each followed by a question about the respondent's satisfaction with the situation. Preset response categories were: satisfied; satisfied, but with reservations; not satisfied; unsure. No question was asked about subsection 2 because this is not formally a core part of advisory group work and whether respondents would perceive this area as relevant to their advisory group could not be predicted.

the person with lead responsibility for the advisory group. These questionnaires were addressed to the chief executives or general managers. If they did not regard themselves as appropriate respondents, they were asked to provide the name and designation of the appropriate person.

As the entire populations of both respondent groups were included in the study, piloting the questionnaires with equivalent samples was not possible. Instead, draft questionnaires were tested and discussed with various people $(n=8)$ involved with advisory groups in other ways and modified on the basis of their comments. The final questionnaires for advisory groups and family health services authorities differed in detail but dealt with essentially the same ground. The box shows the main domains of the two questionnaires and the differences between them.

Responses to the closed questions were coded, entered on to a database and verified, and frequency data were produced. Responses from the same districts for advisory groups and family health services authorities were crosstabulated to compare perceptions and investi- gate possible associations between advisory group activities and satisfaction of family health services authority respondents. The content of responses to the open ended questions were analysed by hand. Themes were identified and responses categorised by $\mathrm{CH}$ and $\mathrm{DB}$ independently; subsequent comparison of the themes showed close agreement.

\section{Results}

RESPONDENTS

We identified 96 family health services authorities and 98 advisory groups (in two places two advisory groups were linked to the same family health services authority) and obtained a response rate of $85(89 \%)$ for the family health services authorities and $90(92 \%)$ for the advisory groups. A completed questionnaire was received from either the advisory group or the authority in every district, and in 79 districts responses were obtained from both. Of the 85 authority questionnaires returned, $47(55 \%)$ were completed by chief executives or general managers, $15(18 \%)$ by medical advisers or directors, $9(11 \%)$ by directors of primary care development, and $14(16 \%)$ by directors of quality or strategy or directors of public health. Of the 90 advisory group questionnaires returned, $85(94 \%)$ were completed by advisory group chairs and the remainder by other members or employees. Most respondents to each questionnaire had been in post for one year or more, but 12 authority respondents and one advisory group chair had been appointed more recently.

ADVISORY GROUP STRATEGIES FOR PROMOTING AUDIT

Respondents' views as to what the advisory group should be doing about audit were generally similar and broadly consistent with current policy (table 2). Both groups of respondents were more likely to emphasise multidisciplinary audit, interface audit between primary and secondary care, and topics of local concern, although the authority's emphasis on these was more marked. For both advisory group and authority respondents unidisciplinary audit was the category least often mentioned as a priority. Both groups singled out audit between general practice and community services for future development.

Thirty eight $(45 \%)$ authority respondents volunteered concerns about the way the advisory groups' audit activities were evolving. The two main problems they identified were that these were based neither on family health services authority priorities nor on areas of more general concern in primary care and that the advisory group was not paying sufficient attention to practices that were not doing audit. Forty one (46\%) advisory group respondents also expressed anxieties about the direction of advisory group audit work, but their concerns were rather different. The main themes were worry about losing their independence from the family health services authority and forfeiting the support of their general practice constituents by moving too far away from practice interests. 
Table 2 Present and future priorities for advisory groups. Figures are numbers (percentages) of respondents

\begin{tabular}{|c|c|c|c|c|}
\hline \multirow[t]{2}{*}{ Aspect of audit } & \multicolumn{2}{|c|}{ Authority respondents $(n=85)$} & \multicolumn{2}{|c|}{ Advisory group respondents $(n=90)$} \\
\hline & $\begin{array}{l}\text { Present and } \\
\text { future priorities }\end{array}$ & $\begin{array}{c}\text { Future but not } \\
\text { present prionities }\end{array}$ & $\begin{array}{l}\text { Present and } \\
\text { future priorities }\end{array}$ & $\begin{array}{c}\text { Future but not } \\
\text { present priorities }\end{array}$ \\
\hline $\begin{array}{l}\text { Focus for projects: } \\
\text { Individual practice audit } \\
\text { Interpractice audit } \\
\text { Districtwide audit }\end{array}$ & $\begin{array}{l}53(62) \\
25(29) \\
44(52)\end{array}$ & $\begin{array}{c}2(2) \\
14(16) \\
9(11)\end{array}$ & $\begin{array}{l}40(44) \\
36(40) \\
37(41)\end{array}$ & $\begin{array}{l}2(2) \\
6(7) \\
6(7)\end{array}$ \\
\hline $\begin{array}{l}\text { Professional groups involved: } \\
\text { Single discipline } \\
\text { Multidiciplinary } \\
\text { Primary/secondary care } \\
\text { General practice/community services }\end{array}$ & $\begin{array}{l}26(31) \\
52(61) \\
52(61) \\
28(33)\end{array}$ & $\begin{array}{l}1(1) \\
8(9) \\
10(12) \\
22(26)\end{array}$ & $\begin{array}{l}23(26) \\
45(50) \\
44(49) \\
35(39)\end{array}$ & $\begin{array}{c}0(0) \\
4(4) \\
7(8) \\
25(28)\end{array}$ \\
\hline $\begin{array}{l}\text { Audit topics: } \\
\text { Individual/practice interests } \\
\text { Topics of local concern } \\
\text { Topics of national concern }\end{array}$ & $\begin{array}{l}38(45) \\
52(61) \\
32(38)\end{array}$ & $\begin{array}{c}3(4) \\
10(12) \\
8(9)\end{array}$ & $\begin{array}{l}38(42) \\
43(48) \\
39(43)\end{array}$ & $\begin{array}{l}1(1) \\
4(4) \\
3(3)\end{array}$ \\
\hline
\end{tabular}

Table 3 Wider quality issues: present and potential advisory group involvement. Figures are numbers (percentages) of respondents

\begin{tabular}{|c|c|c|c|c|}
\hline \multirow[t]{2}{*}{$\begin{array}{l}\text { Advice or help for family health } \\
\text { services authority }{ }^{\star}\end{array}$} & \multicolumn{2}{|c|}{ Advisory group presently involved } & \multicolumn{2}{|c|}{$\begin{array}{l}\text { Advisory group not presently involved but } \\
\text { such involvement would be appropriate }\end{array}$} \\
\hline & $\begin{array}{l}\text { Advisory group } \\
\text { respondents }(n=90)\end{array}$ & $\begin{array}{l}\text { Authority } \\
\text { respondents }(n=85)\end{array}$ & $\begin{array}{l}\text { Advisory group } \\
\text { respondents }\end{array}$ & $\begin{array}{l}\text { Authority } \\
\text { respondentst }\end{array}$ \\
\hline $\begin{array}{l}\text { Evaluate changes in service provision } \\
\text { Identify opportunities for service } \\
\text { innovation }\end{array}$ & $\begin{array}{l}28(31) \\
38(42)\end{array}$ & $\begin{array}{l}25(29) \\
25(29)\end{array}$ & $\begin{array}{l}31 / 62(50) \\
23 / 52(44)\end{array}$ & $\begin{array}{l}32 / 60(53) \\
41 / 60(68)\end{array}$ \\
\hline $\begin{array}{l}\text { Identify practice needs } \\
\text { Evaluate demands from practices } \\
\text { Develop guidelines } \\
\text { Develop quality initiatives - for } \\
\text { example total quality management }\end{array}$ & $\begin{array}{l}59(66) \\
27(30) \\
63(70) \\
40(44)\end{array}$ & $\begin{array}{l}36(42) \\
11(13) \\
57(67) \\
29(34)\end{array}$ & $\begin{array}{l}16 / 31(52) \\
19 / 63(30) \\
13 / 27(48) \\
26 / 50(52)\end{array}$ & $\begin{array}{l}24 / 49(49) \\
28 / 74(38) \\
18 / 28(64) \\
34 / 56(61)\end{array}$ \\
\hline
\end{tabular}

*Categories based on suggestions by respondents in a study in 1992-3 for possible areas of collaboration between advisory group and family health services authority.

tDenominator varies owing to including only respondents whose advisory groups were not presently involved.

Forty four (52\%) authority respondents were satisfied without reservation with the advisory groups' strategy for audit and most of the rest were satisfied, with reservations. Seven $(8 \%)$ respondents were dissatisfied. Although this number is very small, it is worth noting that these respondents were much less likely than those who were satisfied to believe that their advisory groups were presently engaged in promoting audit across professional boundaries (four (57\%) of the dissatisfied respondents as against $41(93 \%)$ of those who were satisfied), between primary and secondary care (three $(43 \%)$ of the dissatisfied respondents as against $40(91 \%)$ of those who were satisfied), or between general practice and community services (two (14\%) of the dissatisfied respondents as against $24(55 \%)$ of those who were satisfied). To some extent these perceptions appear to be correct, insofar as advisory group respondents in the seven "dissatisfied family health services authority" districts were also substantially less likely to state that their advisory groups were doing interface audit of any kind. However, where multidisciplinary audit was concerned, all the advisory group respondents in these districts claimed that their advisory groups were engaged in such work. The discrepancy between satisfied and dissatisfied authority respondents may be a consequence of dissatisfied respondents being less aware of what their advisory groups were doing, rather than any real difference in activity on the part of those groups.

WIDER QUALITY ISSUES

The involvement of advisory groups with their family health services authorities in wider areas was quite extensive (table 3 ). In almost every category listed in the questionnaire most advisory group and authority respondents said either that their advisory group was already involved or, if it was not, thought that involvement of this sort would be appropriate. However, perceptions of the present involvement of advisory groups differed between the two groups, with advisory group respondents being consistently more likely to say that they were already participating in such work. This discrepancy may reflect different interpretations of what the advisory group was doing or lack of awareness of authority respondents of help that was being provided by the advisory group. Although interest in an expanded remit was widespread, not all advisory group respondents were keen to develop the advisory group's work in these areas and $24(27 \%)$ mentioned specific concerns about the risks of blurring the distinction between educational and contractual audit, becoming the family health services authority's "detective arm" and thereby losing the confidence of local practices.

Authority respondents were not asked directly about their satisfaction with the advisory group's activities in respect of these wider quality issues. However, there was some evidence of an association between their perceptions of the extent of advisory group activity in these categories and their satisfaction with the opportunities for family health services authority input into advisory group plans. For example, only one $(7 \%)$ of the 14 authority respondents who were dissatisfied with their opportunities for input thought the advisory group was helping them in identifying practice needs compared with $28(60 \%)$ of the 
Table 4 Information collected by advisory groups and communicated to family health services authorities and what family health services authorities would find valuable. Figures are numbers (percentages) of respondents

\begin{tabular}{|c|c|c|c|}
\hline Type of information or data & $\begin{array}{l}\text { Advisory group } \\
\text { collecting information } \\
(n=90)\end{array}$ & $\begin{array}{l}\text { Advisory group making } \\
\text { such information available to } \\
\text { family health services authority } \\
\qquad(n=90)\end{array}$ & $\begin{array}{l}\text { Authority respondents who find } \\
\text { or would find such } \\
\text { information valuable } \\
(n=85)\end{array}$ \\
\hline \multicolumn{4}{|l|}{ Anonymised data on: } \\
\hline Number of practices auditing & $88(98)$ & $82(91)$ & $76(89)$ \\
\hline Number of audits per practice & $76(84)$ & $23(26)$ & $47(55)$ \\
\hline Topics audited (practice based and interface) & $84(93)$ & $67(74)$ & $79(93)$ \\
\hline Practice progress around audit cycle & $73(81)$ & $41(46)$ & $37(44)$ \\
\hline Outcome of audit (change achieved) & $71(79)$ & $41(46)$ & $80(94)$ \\
\hline Staff involved in audit & $66(73)$ & $35(39)$ & $51(60)$ \\
\hline Attitudes to audit & $59(66)$ & $37(41)$ & $31(37)$ \\
\hline Attitudes to the advisory group & $57(63)$ & $32(36)$ & $33(39)$ \\
\hline Characteristics of non-auditing practices & $41(46)$ & $19(21)$ & $55(65)$ \\
\hline \multicolumn{4}{|l|}{ Anonymised details of: } \\
\hline Requests for advisory group help & $74(82)$ & $32(36)$ & $34(40)$ \\
\hline $\begin{array}{l}\text { Problems faced by practices in carrying out } \\
\text { audit }\end{array}$ & $70(78)$ & $45(50)$ & $70(82)$ \\
\hline $\begin{array}{l}\text { Financial support given to practices } \\
\text { Practical help given to practices }\end{array}$ & $\begin{array}{l}77(86) \\
82(91)\end{array}$ & $\begin{array}{l}60(67) \\
44(49)\end{array}$ & $\begin{array}{l}51(60) \\
47(55)\end{array}$ \\
\hline $\begin{array}{l}\text { Educational activities for general } \\
\text { practitioners organised by advisory group }\end{array}$ & $87(97)$ & $72(80)$ & $61(72)$ \\
\hline $\begin{array}{l}\text { Educational activities for private health care } \\
\text { team members }\end{array}$ & $76(84)$ & $64(71)$ & $56(66)$ \\
\hline $\begin{array}{l}\text { Participation in advisory group educational } \\
\text { activities }\end{array}$ & $76(84)$ & $48(53)$ & $52(61)$ \\
\hline $\begin{array}{l}\text { Participant feedback on advisory group } \\
\text { educational activities }\end{array}$ & $70(78)$ & $38(42)$ & $48(57)$ \\
\hline
\end{tabular}

47 who were satisfied in this respect. None of the dissatisfied respondents thought the advisory group was involved in developing quality initiatives against $22(47 \%)$ of those who were satisfied. Only five $(36 \%)$ of the dissatisfied respondents felt the advisory group was helping them to develop guidelines against $35(74 \%)$ of those were satisfied. Responses from the advisory groups confirmed that advisory group involvement with the family health services authority in all the categories listed in table 3 was indeed lower in the 14 "dissatisfied family health services authority" districts. However, there was also a consistent tendency for satisfied authority respondents to overestimate their advisory group's involvement in these areas and for dissatisfied authority respondents to underestimate what their advisory group was doing.

\section{INFORMATION AVAILABLE ABOUT ADVISORY GROUPS' ACTIVITIES}

Most advisory groups collected a wide range of different types of information about their own activities and the audit activities of their constituent practices, but much of this information was not communicated to the family health services authority. For many of the categories of data (table 4) rather more authority respondents wanted information than seemed to be receiving it and in a few cases, such as audit outcomes, audit topics, and characteristics of non-auditing practices, the shortfall was substantial.

Thirty nine (46\%) authority respondents and $48(53 \%)$ advisory group respondents expressed doubts about the adequacy of the information that was available about progress with audit. The main concern of the authority respondents was insufficient information from the advisory group in relation to outcomes of audit to know whether the money invested was resulting in real improvements in patient care. Some respondents also commented on the shortage of data which would show progress with audit in individual practices. For their part, advisory group respondents emphasised the limitations of the methods available for measuring or recording activity; the difficulties of obtaining robust, reliable, and appropriate information from practices; and the particular problems of measuring outcomes.

Only $31(37 \%)$ authority respondents were satisfied without reservation with the information available to them and $14(17 \%)$ were dissatisfied. For almost every category of data the dissatisfied respondents were less likely than the satisfied respondents to be receiving information from their advisory groups. They also seemed to have slightly different information requirements. For example, they were much more likely to want information on the characteristics of non-auditing practices (12(86\%) dissatisfied respondents $v 17(54 \%)$ satisfied respondents) and yet none of their advisory groups were said to be providing this information, compared with $11(35 \%)$ of the advisory groups in the "satisfied family health services authority" districts.

MECHANISMS FOR MAINTAINING CONTACT BETWEEN ADVISORY GROUP AND FAMILY HEALTH SERVICES AUTHORITY

Respondents were asked which of a list of possible forms of contact applied in their district and which they found valuable (table 5). The discrepancy between the proportions of advisory group and authority respondents who said that family health services authority managers or staff were advisory group members seems to be attributable to confusion over the categories of manager, staff, and medical adviser and between membership of the advisory group and observer status. When the first three categories in table 5 are considered together $82 \%$ of both groups (74 advisory group and 70 authority respondents) seemed to regard the family health services authority as having a presence of one or more of these kinds within the advisory group.

Although practically all advisory groups provided their family health services authority 
Table 5 Forms of contact between advisory group and family health services authority: frequency and perceived value. Figures are numbers (percentages) of respondents

\begin{tabular}{|c|c|c|c|c|}
\hline \multirow[t]{2}{*}{ Form of contact } & \multicolumn{2}{|c|}{ Applies in this district } & \multicolumn{2}{|c|}{$\begin{array}{l}\text { Proportion of those where it } \\
\text { applies who find it valuable }\end{array}$} \\
\hline & $\begin{array}{l}\text { Advisory group } \\
\text { respondents } \\
(n=90)\end{array}$ & $\begin{array}{l}\text { Authority } \\
\text { respondents } \\
(n=85)\end{array}$ & $\begin{array}{l}\text { Advisory group } \\
\text { respondents }\end{array}$ & $\begin{array}{l}\text { Authority } \\
\text { respondents* }\end{array}$ \\
\hline $\begin{array}{l}\text { Family health services authority manager/staff member is } \\
\text { advisory group member }\end{array}$ & $14(16)$ & $28(33)$ & $10 / 14(71)$ & $18 / 28(64)$ \\
\hline $\begin{array}{l}\text { Family health services authority adviser is advisory group } \\
\text { member }\end{array}$ & $49(54)$ & $49(58)$ & $30 / 49(61)$ & $32 / 49(65)$ \\
\hline $\begin{array}{l}\text { Family health services authority has observer status at } \\
\text { advisory group meetings }\end{array}$ & $25(28)$ & $20(24)$ & $14 / 25(56)$ & $9 / 20(45)$ \\
\hline $\begin{array}{l}\text { Family health services authority receives written reports of } \\
\text { advisory group meetings }\end{array}$ & $36(40)$ & $35(41)$ & $6 / 36(17)$ & $7 / 35(20)$ \\
\hline $\begin{array}{l}\text { Family health services authority receives advisory group } \\
\text { annual report }\end{array}$ & $89(99)$ & $84(99)$ & $32 / 89(36)$ & $34 / 84(40)$ \\
\hline $\begin{array}{l}\text { Family health services authority manager and advisory } \\
\text { group chair have regular meetings }\end{array}$ & $45(50)$ & $63(74)$ & $31 / 45(69)$ & $40 / 63(63)$ \\
\hline $\begin{array}{l}\text { Family health services authority manager and advisory } \\
\text { group members/staff have informal contact }\end{array}$ & $57(63)$ & $68(80)$ & $32 / 57(56)$ & $24 / 68(35)$ \\
\hline
\end{tabular}

*Denominator varies owing to including respondents who had this type of contact.

with an annual report, fewer than half of the advisory group or authority respondents identified this as valuable. In contrast, formal personal contact between advisory group and family health services authority through regular meetings or family health services authority representation within advisory group was rated highly by most of those who had these, but such contact did not occur in all districts. In addition to those forms of contact specifically asked about, some advisory group and authority respondents mentioned the benefits of regular meetings between family health services authority staff and advisory group staff and of advisory group members attending family health services authority board meetings to present and answer questions about advisory group work.

Forty five (50\%) advisory group respondents and $48(57 \%)$ authority respondents said the advisory group and family health services authority had a formal agreement (usually a business plan) about what the advisory group would do in 1994-5. Most of these agreements were viewed by both parties as beneficial in clarifying objectives and helping to provide direction for the advisory group. However, some advisory group respondents were concerned about the restrictive and inflexible nature of formal agreements and the increased opportunities they provided for unwanted management intervention. In contrast, authority respondents saw the potential for greater management involvement as a positive feature in helping the development of a common agenda. Generally, the authority respondents mentioned very few disadvantages.

Only four $(9 \%)$ of the 45 advisory group respondents without existing agreements thought that an agreement would be useful against $18(49 \%)$ of the 37 family health services authority managers who did not have one. Most advisory group respondents without agreements thought the disadvantages of greater family health services authority intervention would outweigh any potential benefits and several authority respondents were also concerned that requiring such an agreement might damage the relationship they had built up with the advisory group. A minority of both groups gave more positive reasons for not developing agreeements. They were pleased with how things were going and saw no benefit in formalising a flexible relationship that was already working well on the basis of mutual confidence.

Fifty (59\%) authority respondents and $48(53 \%)$ advisory group respondents expressed specific concerns about the mechanisms for maintaining contact. The main problems identified by authority respondents were that contact was too limited and that there was insufficient coordination of activities between advisory group and family health services authority. Although some advisory group respondents shared these views, others were concerned that any closer contact might be used by the family health services authority to exert inappropriate control over the advisory group, and some felt this had already happened.

Forty one (48\%) authority respondents were satisfied without qualification with the arrangements for maintaining contact with the advisory group and $12(14 \%)$ were dissatisfied. None of those who were dissatisfied were members of their advisory groups compared with $16(39 \%)$ of those who were satisfied and several specified that they would like to be. Only six $(50 \%)$ of the dissatisfied respondents had regular meetings with their advisory group chair, against $40(98 \%)$ of those who were satisfied. Only four $(33 \%)$ of the dissatisfied respondents said their medical adviser was a member of the advisory group compared with $21(51 \%)$ of those who were satisfied. Dissatisfied respondents were also less likely to receive regular written reports of advisory group meetings than satisfied respondents (two $(17 \%) v 17(41 \%)$ respectively). It should be noted, however, that some authority respondents whose formal contact with their advisory group was just as limited did not identify this as a problem.

\section{PLANNING FUTURE WORK OF ADVISORY} GROUPS

We focused on the financial year 1994-5, which had just begun at the time of the survey, to find out how far family health services authorities had been involved in planning the advisory group's strategy for the coming year. 
Nearly all advisory groups had already set their objectives for the year and the remainder were in the process of doing so. Seventy four $(87 \%)$ of the authority respondents thought their views had been sought and $70(82 \%)$ believed they had been taken account of in some way by the advisory group. Forty seven (55\%) thought family health services authority priorities had been explicitly incorporated into advisory group plans, but from the advisory group responses it seemed that what this meant was very variable. Generally, suggestions from the family health services authority seemed to be adopted to the extent that they coincided with the advisory group's own views. Thirty three $(39 \%)$ of the authority respondents mentioned specific concerns about their opportunities to influence advisory group plans. The main problems identified were the lack of adequate formal arrangements for family health services authority input, the fragility of agreements dependent on good will, and the constraints on communication imposed by advisory groups' preoccupations with confidentiality.

Forty seven (55\%) of the authority respondents were satisfied with the family health services authority's opportunities for input into advisory group plans and $14(17 \%)$ were dissatisfied. The dissatisfied respondents were much less likely to believe that their views had been taken account of by the advisory group than the satisfied respondents (five $(36 \%) v$ $43(91 \%)$.

\section{FAMILY HEALTH SERVICES AUTHORITY}

SATISFACTION WITH ADVISORY GROUPS

Table 6 summarises the data on satisfaction of family health services authorities with advisory groups. Overall, authority respondents seemed to be reasonably satisfied, some were fulsome in their praise: "I am always amazed by the wide scope that the advisory group covers. We are lucky to have a band of real enthusiasts who really do manage to cover a demanding agenda successfully." However, 23(27\%) authority respondents were not satisfied in at least one area and $14(16 \%)$ of these were dissatisfied in more than one.

Satisfaction among authority respondents and the size of the district (number of practices) or whether the district was predominantly rural or urban was not associated. Rather, the respondents' comments indicate that satisfaction depended on the compatibility between the views of the family health services authority and advisory group of the role of the advisory group. Although many of the authority respondents would like advisory group and family health services authority to develop a more integrated or coordinated strategy than had been agreed so far, most were aware of the sensitivities surrounding medical audit and accepted that progress might be slower than they would like. The relative freedom that advisory groups have so far had to develop their own agendas was seen as "a price worth paying" in the short term to get audit soundly established in general practice. Some authority respondents valued the flexibility of the arm's length relationship they had developed with the advisory group and were happy to maintain this, but most were beginning to formalise arrangements or were expecting to be able to do so. Those who were happy with the current status of a semi-independent advisory group or who thought that the advisory group was progressing at a reasonable pace towards a more cooperative model were generally satisfied. Those who thought the advisory group was moving unnecessarily slowly were more likely to express frustration with what they saw as excessive caution. A few authority respondents were sceptical about the prospects of ever developing closer collaboration because of what they saw as inappropriate ideas about the advisory group's role: "The advisory group believes that it is not a subcommittee but quasi-autonomous and that it should decide how it spends the totality of its financial allocation. It is resistant to any direct input from the family health services authority, which it regards as interference. There is a degree of paranoia." A few family health services authorities had dealt with what they regarded as intolerably unbiddable advisory groups by taking direct control and restructuring the group. At the time of this survey one advisory group had ceased to function as a consequence of such action because nobody was prepared to act as chair.

\section{Discussion}

The family health services authority respondents in this study had considerable expectations of their advisory groups, wanting them both to develop their audit activities in line with current policy and to broaden their contribution beyond audit into wider areas of quality. Most advisory groups seemed to share these interests and aspirations and have already expanded the scope of their audit activities to incorporate multidisciplinary perspectives and topics of local or national interest. In addition to audit, a substantial proportion of advisory groups have begun to help their family health services authorities in a wide variety of quality assurance and provider development activities

Table 6 Family health services authority $(n=85)$ satisfaction with the advisory group in four domains. Figures are numbers (percentages) of respondents

\begin{tabular}{|c|c|c|c|c|c|}
\hline & Satisfied & $\begin{array}{l}\text { Satisfied with } \\
\text { reservations }\end{array}$ & Not satisfied & Unsure & No response \\
\hline Strategy for promoting audit & $44(52)$ & $30(35)$ & $7(8)$ & $2(2)$ & $2(2)$ \\
\hline $\begin{array}{l}\text { Type of information provided to family health services } \\
\text { authority about activities and local progress with audit }\end{array}$ & $31(37)$ & $40(47)$ & $14(17)$ & 0 & 0 \\
\hline $\begin{array}{l}\text { Present arrangements for maintaining contact with the } \\
\text { advisory group }\end{array}$ & $41(48)$ & $32(38)$ & $12(14)$ & 0 & 0 \\
\hline $\begin{array}{l}\text { Family health services authority's opportunities to have } \\
\text { input into the advisory group's planning of subsequent } \\
\text { year's work }\end{array}$ & $47(55)$ & $24(28)$ & $14(17)$ & 0 & 0 \\
\hline
\end{tabular}


and many more are interested in developing such joint initiatives. However, in their comments advisory group respondents made it clear that they regard these developments as expanding rather than replacing the advisory group's original role of facilitating practice based audit and are concerned not to jeopardise this core function.

The quality and availability of information about the advisory group's progress with audit attracted the most concern from managers and problems relating to this were also recognised by advisory group chairs. The shortage of valid and informative meaures of audit activity and audit outcomes and the specific difficulties advisory groups face in obtaining reliable data are widely recognised. ${ }^{8}$ Nevertheless, most advisory groups seem to be collecting and collating a wide range of different types of information. However, much of these data are not passed on to the family health services authority. Whether this is because of doubts about the validity or utility of the data, lack of resources within the advisory group to process them appropriately, or concerns about breaching confidentiality is not clear.

Many advisory groups have now developed more formal and systematic links with family health services authority management than were originally envisaged and, mostly, these are regarded as beneficial. In particular, regular, direct personal contact is widely valued. The main benefit of increased contact seems to be better communication. In some districts information exchange and contact remain more limited and often this seems to be associated with dissatisfaction. However, whether the lack of contact is the cause or simply a symptom of problems in the relationship between advisory group and family health services authority is not clear. Managers who are dissatisfied may also be more demanding and some advisory groups may have reacted to what they regard as excessive or inappropriate expectations by taking extra care to keep their distance. Certainly the reverse seems to be true: several advisory group respondents commented that it was because they felt able to trust the family health services authority that they were willing to work more closely with it.

Although most family health services authority respondents see the family health services authority as having some influence on advisory group strategy, the extent to which family health services authorities directly affect their advisory groups' plans is not clear. Advisory groups and family health services authorities seem to have much in common in terms of shared priorities for audit, but this may have relatively little to do with successful negotiation. Rather, both groups seem to be moving independently in similar directions in response to the wider health agenda and the evident needs of local primary care.

Given the sensitivities surrounding medical audit and the unique status of an advisory group as a statutory, yet semi detached, professional subcommittee of the family health services authority, it has been apparent from the start that constructive partnerships between advisory group and family health services authority would require a degree of good will and accommodation on both sides. The evidence from this study suggests that most advisory groups have succeeded in developing work programmes which have kept up with the changing brief for audit and continue to be regarded as appropriate and relevant by managers. Although some managers would certainly like tighter formal control over local audit policy, the flexibility of the original advisory group brief seems to have served many districts well, enabling the development of locally acceptable arrangements that would be difficult to specify in national legislation.

Several family health services authority and advisory group respondents expressed uncertainty and concern about what would happen to the advisory group and to audit generally when family health services authorities and district health authorities merge, and for some the disruption had already begun. The challenge for the future will be to ensure that any new arrangements build on the experience gained by advisory groups and family health services authorities' in working together, so that the positive features of their relationships can be maintained and lessons learnt where problems have arisen.

This study was funded by the Department of Health.

1 Secretaries of State for Health, Wales, Northern Ireland, and Scotland. Working for patients. London: HMSO, 1989. (Cm 555.)

2 Department of Health. Health service development - working for patients. Medical audit in the family practitioner services. for patients. Medical audit in the family pron

3 NHS Management Executive. Clinical Audit. Meeting and improving standards in health care. Leeds: Department of Health, NHS Management Executive, 1993.

4 NHS Management Executive. Clinical Audit: 1994/95 and beyond. Leeds: Department of Health, 1994.

5 Field R. Letter to chairmen of advisory groups. 16 May 1994.

6 Humphrey C, Berrow D. Developing role of medical audit advisory groups. Quality in Health Care 1993;2:232-8

7 Primary Health Care Clinical Audit Working Group of the Clinical Outcomes Group. Clinical audit in primary health care. London: Department of Health, 1995. (Report to the Clinical Outcomes Group.)

8 Humphrey C, Berrow D. Medical audit in primary care. $A$ collaboration of evaluative projects, 1991-3. Leeds: NHS Management Executive, 1994. 